\section{Memorias y testimonios en torno a la militancia peronista en Bahía Blanca (Argentina) durante la
década del 70}

Memories and testimonies in relation to the peronist militancy in Bahía Blanca during the 70's

\section{GaBRIELA GonZÁLEZ*}

\section{Resumen}

A partir del presente trabajo nos proponemos abordar determinadas experiencias de militancia dentro del peronismo en la ciudad de Bahía Blanca (Argentina), durante la década del setenta. Partiendo de una perspectiva etnográfica, destacamos la centralidad de los discursos nativos en el proceso de construcción de las memorias presentes sobre dicho pasado.

Universidad Nacional del Sur - CONICET. Pasaje Jorge Harding 1343 (2000), Rosario, Santa Fe, Argentina. Correo electrónico: glgonza2@yahoo.com.ar
De aquí se desprenden una serie de preguntas que guían gran parte de nuestra búsqueda: cómo se relacionaron las experiencias de vida cotidiana y la militancia con procesos históricopolíticos más amplios, cómo se insertaba la militancia y la política en la vida de un sujeto, y cómo hoy se reconstruyen esas experiencias.

Palabras clave: etnografía, memoria, militancia, política.

\section{Abstract}

With this study we aim to address certain experiences of activism inside peronism in the city of Bahía Blanca (Argentina), during the late seventies. From an ethnographic perspective, we highlight the centrality of native discourses in the process of building these memories about that past. Hence, a series of questions that guide an important part of our search emerge: how the experiences of everyday life and militancy related to broader historical and political processes, and how political militancy was inserted in the life of a subject, and how these experiences are reconstructed today.

Key words: ethnography, memory, militancy, politics.

\section{A modo de introducción}

Desde hace algunas décadas el pasado reciente se ha vuelto foco de interés y, por ende, plausible de ser aboradado desde diversas perspectivas teóricas. Esperamos poder realizar un aporte más en este sentido, teniendo en cuenta las posibilidades que una mirada etnográfica abre hacia el análisis de dicho pasado. Se trata 
entonces de detenernos en la problemática de las memorias sobre la militancia peronista, a través del diálogo permanente entre la teoría y el trabajo de campo, es decir, entre los discursos y categorías nativas y la aproximación crítica del investigador a aquella realidad que busca aprehender. Dos cuestiones a destacar subyacen al respecto, por un lado, la complejidad del mundo social y sus contradicciones presentes en dicho diálogo y, por otro, la valoración sobre las afirmaciones de los sujetos sobre sus propias acciones (Balbi 2007). De esta manera, este trabajo recupera un enfoque de la Antropología de la Política y, desde ahí, propone un abordaje relacional de los procesos sociales y cotidianos en torno a la militancia política.

Nuestro interés se centra en la reconstrucción de la memoria de un sujeto político particular, cuya práctica de militancia se encuentra atravesada por un momento determinado de la historia argentina, y por la singularidad del contexto local donde las mismas tienen lugar. A continuación detallaremos brevemente algunos puntos nodales para nuestro trabajo, en torno a la relación entre memoria y testimonio, para enfocarnos luego en esa singularidad atribuida a la ciudad de Bahía Blanca.

\section{Algunas caracterizaciones acerca de la relación entre memoria y testimonio como herramienta para el abordaje del pasado}

La relación entre memoria y testimonio en la reconstrucción del relato histórico sobre el pasado ha formado parte de numerosos debates y caracterizaciones. Nos gustaría mencionar algunas de ellas, en tanto encontramos en el testimonio una herramienta metodológica importante para abordar la problemática de la memoria. Dicha opción retoma, a su vez, los planteos de Pilar Calveiro, para quien el testimonio, en el caso argentino, constituye una práctica signada políticamente y direccionada de manera específica y posee, además, "una "valencia" política: el lugar que se le asignará a la resistencia en la construcción de la historia del terrorismo de Estado, como relato de "verdad" socialmente validado" (2006a: 65).

Entendido como un instrumento válido en la reconstrucción del relato histórico, Michael Pollak y Natalie Heinich afirman que el testimonio pone en juego tanto la memoria como una reflexión sobre sí por parte del sujeto, esto es, la propia identidad, y que "todo testimonio se ancla también y sobre todo en las condiciones sociales que lo vuelven comunicable" (1986: 3). De esta manera, la recuperación de la experiencia del sujeto militante, por medio del relato testimonial, nos habla de unas memorias entendidas, inicialmente, como relato transmitido por "aquellos que lo vivieron", pero, en tal sentido, no como relato petrificado, inmóvil, siempre igual a sí mismo.

Esta valorización del relato testimonial de la propia experiencia se enmarca en lo que Beatriz Sarlo (2005) denomina como "giro subjetivo", un cambio en las formas de abordar el pasado que juzga, según la autora, a las fuentes testimoniales como más "reveladoras". Esta tendencia académica actual, de acuerdo a Sarlo, es producto del reordenamiento ideológico y conceptual de la sociedad, del pasado y de los sujetos que buscan, ya conservar el recuerdo, ya reparar una identidad lastimada. Sarlo (2005) pareciera así ubicar el relato testimonial en el lugar de una moda de época, más allá de que advierta que la forma de 
este tipo de discurso se explica a través de su producción y condiciones culturales y políticas que lo hacen más o menos creíble.

En este punto quisiéramos retomar la cuestión del tiempo, ya que experiencia y narración se inscriben en una temporalidad que vuelve más compleja la manera de hallarse frente a la memoria, en un sentido figurativo. Tanto experiencia como narración se ubican en momentos particulares, la una en el de su acontecer y posterior recuerdo y/o reconstrucción, la otra en el de su repetición/reactualización (Sarlo 2005). Ahora bien, en tanto el relato es reactualizado en cada enunciación y, al igual que la experiencia, el mismo se encuentra condicionado contextual, cultural y políticamente ¿puede dicha experiencia ser re-presentada a través del discurso? ${ }^{1}$ Esta pregunta encierra una doble acepción, por un lado, el hecho de que toda experiencia es transmisible, por otro, que el testimonio puede representar todo lo que la experiencia fue para el sujeto. Si, como sostiene Pilar Calveiro (2006b), el testimonio es un relato fragmentario que implica la construcción de la experiencia desde coordenadas sociales, no la "calca", esta pregunta podría encontrar aquí su respuesta. La discusión, sin embargo, no se termina en dicha respuesta, sino que se centra ahora respecto del testimonio como "ícono de verdad" en la construcción del pasado (Sarlo 2005).

Para quienes han abordado esta cuestión, todo testimonio plantea una serie de problemas teóricos y metodológicos que emergen al momento de la realización de entrevistas y su posterior interpretación. En este sentido, algunos autores confieren a los testimonios el

Sarlo (2005) equipara discurso de la memoria con testimo- valor de fuente histórica, sin dejar de lado las dimensiones ético-políticas que conllevan su producción e interpretación (Carnovale, Lorenz y Pittaluga 2006). Otros como Pollak y Heinich (1986) lo consideran una fuente de la que habría que diferenciar la necesidad a la cual responde (testimonios judiciales, relatos autobiográficos, relatos históricos). Pilar Claveiro (2006a), a su vez, plantea la centralidad de los testimonios en la construcción histórica. Como primera instancia de esta construcción, vinculada con el terrorismo de Estado en la Argentina de los años setenta, la autora distingue tres momentos que comporta el trabajo emprendido por la memoria: testimonio como ruptura del "silencio oficial", memoria como trama de los relatos de la resistencia, e historia como texto estructurador de alguna verdad.

La problematización de estas diversas interpretaciones, muchas veces pareciera simplificarse a través de la enfatización que se hace de la memoria, o de la validez de los testimonios como un campo de lucha. Se habla, entonces, de memorias o visiones dominantes, que entran en juego tratando de adquirir poder de registro, y de "emprendedores de la memoria", que llevan adelante "proyectos sociales de escucha y rescate" de tales testimonios (Jelin 2009)2. Al ser planteada en estos términos, la definición de memoria que parecería esbozarse dista de otras que plantean la inexistencia de "dueños de la memoria" y el carácter de selectividad que es inherente a la misma.

\footnotetext{
Elizabeth Jelin (2009) plantea que existen distintas iniciativas llevadas a cabo por los "emprendedores de la memoria" que, desde el advenimiento de la democracia, implicaron un giro en el sentido del testimonio, primero de los exiliados y algunos organismos de Derechos Humanos que hicieron visible públicamente la represión, luego por parte de la CONADEP (Comisión Nacional sobre la Desaparición de Personas) y, en tercer lugar, las causas judiciales.
} 
No es ésta, sin embargo, la discusión que quisiéramos plantear, sino la de las modalidades reconstructivas del pasado. Estas modalidades encierran un interés por las historias de vida cotidianas, a partir del uso del relato biográfico como "estrategia de representación" que otorga sentido a la trayectoria de vida de aquel que narra (Oberti y Pittaluga 2006). Este cambio de perspectiva conlleva, para Sarlo (2005), la idea de entender el pasado desde su propia lógica, a la vez que sostiene gran parte de los trabajos de reconstrucción de las décadas del sesenta y setenta. El testimonio abunda en detalles y adjudica un sentido único a la historia, por ello hay que someterlo a la crítica, y confiar menos en la memoria y más en las operaciones de los intelectuales, agrega la autora. Sin dejar de lado la mirada crítica que las "operaciones intelectuales" pueden aportar, la experiencia que es narrada a través del relato biográfico no deja de ser una aproximación a lo acontecido y, por lo tanto, se encuentra en la base del conocimiento (Calveiro 2006b). Adicionalmente, el valor del testimonio es diferente cuando aquella realidad a la que buscamos aproximarnos es definida en términos de genocidio (Vezzetti 2009).

Otro paréntesis que creemos necesario hacer se encuentra en relación con el testimonio en tanto fuente que presenta determinados criterios metodológicos que lo diferencian de otras fuentes, con las cuales, sin embargo, se halla vinculado: las "historias de vida" o "relatos biográficos" (Piña 1988). Siguiendo a Carlos Piña, el relato de vida se caracteriza por la profundidad que se le otorga al recorrido biográfico de uno o varios sujetos, además éste resalta la versión que los sujetos dan de su propias vidas, cuestión que en este trabajo hemos mencionado bajo el nombre de "discursos y categorías nativas", basándonos en Fernando Balbi (2007). El testimonio, en cambio, constituye para Piña el "relato con el cual una persona se refiere, a través de sus propias vivencias personales, a algún suceso histórico o momento social del cual fue testigo" (1988: 4).

Acorde a la problemática de investigación propuesta, podríamos decir que los relatos testimoniales con los que trabajamos constituyen narrativas acerca de la militancia política en Bahía Blanca, y las prácticas y concepciones políticas de los sujetos en torno a ella. En la definición de testimonio recién mencionada, Piña (1988) deja entrever un aspecto importante que luego explicita más adelante en el artículo al que aquí hacemos mención, nos referimos al carácter informativo que constituye la esencia del testimonio. Permítasenos poner entre signos de interrogación esta afirmación, cuando mucho se ha discutido acerca de la memoria como algo abierto, como una construcción presente que, como nos dice Calveiro (2005), se lanza hacia el pasado, recreando viejos y nuevos sentidos. Queremos decir, concebir el testimonio como un instrumento metodológico desde el cual aproximarnos al pasado de manera reflexiva, a partir de aquello que el sujeto restituye en su relato, y no como un corpus de datos acabado.

\section{Bahía Blanca "ciudad vigilada"}

En este apartado nos detendremos brevemente en la reconstrucción del contexto histórico-político de la ciudad de Bahía Blanca, destacando determinados "eventos etnográficos" (Peirano 2001). Éstos sintetizan innumerables factores 
(económicos, culturales, militares, etc.) que creemos no podrían ser explicados de forma aislada.

Esta caracterización pretende, así, dar cuenta de una ciudad cuya historia se remonta hasta entrado el siglo XIX, en el contexto de expansión hacia el sur del territorio argentino, habitado por indígenas que desde mucho tiempo atrás ocupaban dichas tierras. Consideramos significativo remitirnos hasta este periodo, en tanto es hasta allí donde se remonta el origen de la presencia militar en la ciudad. Un origen y posterior desarrollo vinculado con la figura de un "otro" a "desaparecer", en pos de diferentes proyectos contrapuestos.

Durante el primer cuarto del siglo XIX se promovió desde Buenos Aires un proyecto para la apertura de puertos y la fundación de poblaciones hacia las tierras del sur de dicha provincia, las cuales se hallaban ocupadas por pueblos pertenecientes a la cultura tehuelche. Tal proyecto requería la concertación de un tratado de paz con los indígenas que habitaban esas latitudes, pero aún así los primeros intentos no resultaron satisfactorios, produciéndose varios avances que culminaron fracasando.

En ese transcurso por colonizar esta porción del territorio se produjo el reconocimiento de la denominada Bahía Blanca, y en marzo de 1828 fue designado el coronel Ramón Bernabé Estomba quien, el 11 de abril de ese mismo año, echó los cimientos para la construcción de un fuerte ${ }^{3}$. Éste recibió el nombre de Fortaleza Protectora Argentina, en homenaje

La instalación de fuertes hacia el sur del territorio argentino constituyó una demarcación política conocida como "frontera sur". Siguiendo a Carlos Martínez Sarasola, más que un límite fijo, se trató de una frontera político-militar y cultural que dividía al territorio nacional en "dos mundos en pugna" (1998: 81) al General San Martín y, con el correr del tiempo, se transformaría en un poblado bajo la denominación actual de Bahía Blanca.

Entre sus primeros pobladores se encontraban principalmente soldados, algunos funcionarios y prisioneros indígenas (Weinberg et al. 1978). Posteriormente, el gobierno resolvió enviar colonias agrícolas militares que ampliaran las zonas productivas, por lo cual en 1856 arribó la Legión Agrícola Militar, que más tarde daría origen al Primer Batallón del Regimiento 8 de Infantería (Recchi 1995). Si bien este proyecto no tuvo éxito, las autoridades continuaron con el envío de inmigrantes europeos, que permitieran tanto reemplazar la población indígena, como ocupar y poner a producir más tierras ${ }^{4}$.

Hacia fines de 1870 , se dispuso consolidar definitivamente la "línea de frontera", por medio de la facilitación de las comunicaciones terrestres, que aseguraran las expediciones militares ${ }^{5}$. Cabría destacar que, ante este interés por la ocupación del territorio para la obtención de tierras productibles, el resultado final culminó con el genocidio de los indígenas que lo habitaban. En este sentido, consideramos que la instalación militar de la "frontera" sur se halla en estrecha vinculación con un acto autoritario y de exterminio de gran parte de la población indígena.

El envío de colonias militares a la región tuvo lugar con motivo del escaso aumento de la población, a la vez que las acciones de avanzada indígena tampoco disminuyeron. Esta situación se reflejó en lo que fuera el trazado de la nueva frontera en procuración de obtener más tierras que permitan ampliar la producción exportable.

De esta manera, tuvo lugar la llegada del telégrafo militar, del ferrocarril y se habilitó el primer muelle comercial de ultramar para dar salida a los frutos de las futuras colonias. El desarrollo agropecuario y las consiguientes instalaciones portuarias, junto a la red ferroviaria, fueron acentuando su característica de puerto exportador (Weinberg et al. 1978). 
Todas estas transformaciones mencionadas respecto al creciente desarrollo portuario, en conjunto con la eliminación indígena y la puesta en producción de las tierras agrícolas de la región, llevaron a Bahía Blanca a iniciar durante estos años un rápido proceso de modernización y crecimiento demográfico (Cernadas 1971). En ese contexto, y hasta entrado el siglo XX, las tropas militares atravesaron un camino de avance y retirada de la región, hasta que en 1910 se establecieron en Bahía Blanca, Viedma y Neuquén los Distritos Militares, y hacia 1923, la presencia de unidades militares operacionales en la ciudad fue retomada ya $\sin$ interrupción (Recchi 1995).

Los trabajos que caracterizan la historia de Bahía Blanca, durante parte del siglo XIX, y las investigaciones más recientes en torno a su desarrollo y crecimiento (Bustos y Marenco 2000; Marenco 2000; Rodríguez et. al. 2000, entre otros) darían cuenta, de acuerdo a la perspectiva que guía esta investigación, de la transformación de la pequeña población surgida como fuerte, en relación siempre con la presencia de elementos militares. En otras palabras, "lo militar" aparecería como fenómeno constitutivo y constituyente del desarrollo y crecimiento de la ciudad.

Un acontecimiento más que aporta a esta hipótesis, lo constituye la instalación de la Base Naval Puerto Belgrano ${ }^{6}$ en 1898 bajo el impulso del general Julio Argentino Roca, con motivo, por un lado, de la defensa del territorio nacional ante los conflictos existentes con Chile

$6 \quad$ La Base Naval Puerto Belgrano es la principal base de guerra de la Armada Argentina, además de la más grande en Latinoamérica, y se encuentra ubicada a 25 kilómetros de la ciudad de Bahía Blanca. $\mathrm{y}$, por otro, ante la necesidad de un complejo portuario militar que concentrara diques, talleres y arsenales con proyección al océano (Cernadas 1971). La historia de su creación es interesante en dos sentidos, uno porque hace a la trama social de Bahía Blanca, y otro, porque nos permite rastrear el rol que fueron teniendo las Fuerzas Armadas a lo largo del tiempo, en respuesta a ciertos intereses de clase. Para los fines de esta investigación, nos detendremos en este último.

Según Mabel Cernadas, hasta 1890 las fuerzas militares habían tenido un crecimiento irregular, "moviéndose más en la improvisación que en el desarrollo organizado" (1971: 15). Sin embargo, a partir de dicha década, frente a las amenazas de expansión de Chile y su superioridad militar, las fuerzas nacionales iniciaron una etapa de crecimiento, apoyadas tanto por el Congreso de la Nación como por la opinión pública. En dicho contexto, en 1895 se promulgaron una serie de leyes militares para organizar la Guardia Nacional y el Ejército, el cual pasó a estar formado por voluntarios contratados y por argentinos mayores de 20 años (Cernadas 1971). Hacia 1897, se expidió la resolución por la cual al año siguiente se iniciarían los trabajos para la construcción del Puerto Militar, más tarde denominado Puerto General Belgrano ${ }^{7}$. Algunas décadas más tarde Puerto Belgrano, tras la incorporación de aeronaves a la Armada, crearía la Base Aeronaval Comandante Esporå . tores militares que insistían en la inferioridad militar argentina respecto de Chile. Estas tensiones y la agudización de los conflictos con el país vecino, conllevaron la compra de buques y armamentos a Europa, con financiamiento del Estado y de particulares y, además, la sanción de la Ley Orgánica del Ejército, la cual establecía el Servicio Militar Obligatorio (Cernadas 1971).

Su ubicación se encontraría aledaña al Aeródromo Civil de Bahía Blanca, a 5 kilómetros de dicha ciudad (Roa, s/a). En el año 
En este mismo orden de situación, en 1964 se asienta definitivamente el Comando del V Cuerpo de Ejército ${ }^{9}$, el cual desempeñó un papel destacado durante la dictadura militar de 1976.

Si recapitulamos entonces lo concerniente a la historia de Bahía Blanca durante el siglo XIX, ésta habría tenido dos acontecimientos que, de alguna manera, definen parte de su trama social: su fundación como fuerte para controlar el acecho de los "malones indígenas", y la construcción del Puerto Militar frente al peligro de la pretensión chilena sobre los territorios patagónicos. En ambos casos, el objetivo perseguido era la preservación de las tierras que se destinarían a la elaboración de productos exportables. Ya en el siglo XX, la presencia de las Fuerzas Armadas, además de verse incrementada a través de nuevos elementos militares, cobrará un giro en torno de la delimitación de ese "otro" ante quien establecer una nueva "frontera". De ello darán cuenta los sucesivos golpes de Estado en los que éstas participaron de la mano de los sectores más dominantes de la Argentina, en desmedro de vastas capas populares.

A esta trama de fuerte presencia de las Fuerzas Armadas, que en primera instancia haría suponer cuestiones disciplinares de por medio, se podría agregar además una cuestión de orden económica, dado el porcentaje de población civil y militar en relación asalariada con éstas,

2009 Comandante Espora resonaría entre la opinión pública dado que en sus instalaciones se exhibía uno de los aviones que fuera utilizado durante los denominados "vuelos de la muerte".

En sus dependencias funcionó entre los años 1976-1978 el principal Centro Clandestino de Detención de la ciudad de Bahía Blanca, conocido como "La Escuelita". Entre los años 1975 y 1979 sus responsables a cargo fueron el general Acdel Vilas (diciembre de 1975), el general Abel Teodoro Catuzzi (diciembre de 1976) y el general Raúl José Ortiz (diciembre de 1979). sobre todo en la ciudad vecina de Punta Alta, colindante con la Base Naval. Adicionalmente, su fundación abrió camino al crecimiento económico tanto de la ciudad, como de la región, dado que en Bahía Blanca se encuentra uno de los puertos de aguas profundas más importantes del país. Sin embargo, estos hechos no permitirían comprender por sí solos la preeminencia de ciertas normas de conducta acordes con lo militar.

A este respecto, algunos autores destacan el rol de la prensa, no solamente como medio de construcción de opinión, sino además, y sobre todo, como portavoz de las Fuerzas Armadas (Llull 2005; Orbe 2007; Zapata 2007). Se trata en cuestión del diario local La Nueva Provincia, "actor político" destacado durante la dictadura de 1976 (Zapata 2008). Los trabajos llevados adelante en este campo resaltan también la presencia de dos instituciones de gran peso en el desarrollo de la historia de Bahía Blanca, de forma muy marcada en las décadas del sesenta y setenta, a saber, la Iglesia y la universidad. Cabe subrayar, en este contexto, la importancia que estas instituciones tuvieron en el orden nacional. Para dar cuenta de ello creemos necesario ahora poner en relación lo desarrollado hasta aquí con el escenario etnográfico, en el cual se pone en juego la vinculación entre militancia y cotidianeidad por parte de los sujetos.

\section{Escenario etnográfico y práctica militante}

En este apartado nos hemos centrado en determinados procedimientos característicos de los textos etnográficos. Por un lado, hemos cambiado los nombres de todos los sujetos 
que nos han brindado su testimonio ${ }^{10}$, para evitar indiscreciones y malestares que pudieran afectarlos. Cabe aclarar, al mismo tiempo, que los sujetos con quienes interactuamos no constituyen para nosotros objetos de estudio o "informantes". Nuestro interés se centra en las prácticas y concepciones militantes, a las que estos sujetos caracterizan y dan sentido. Por otro lado, en tanto el enfoque en que nos centramos en esta investigación tiene como anclaje principal la consideración de las categorías y discursos nativos, los mismos serán destacados, a lo largo del texto, con letra itálica. En cambio, las categorías provenientes de la teoría analítica, se hallan identificadas entre comillas, al igual que las citas textuales que no posean más de tres renglones.

Entendemos por escenario etnográfico el vínculo entre el contexto social y el texto, es decir, aquello que los sujetos reconstruyen de ese contexto a través de su enunciación. De esta manera, nos centramos en algunos de los testimonios que hemos recogido, los mismos se remontan al golpe de Estado de 1955 y las consiguientes consecuencias del derrocamiento del general Perón y la proscripción del peronismo, con lo cual, tanto en Bahía Blanca como en el resto del país, las representaciones acerca de la realidad aparecen, en gran medida, mediadas por el binomio peronismo/antiperonismo.

Yo tengo un tío, concretamente un tío que era de la marina y fue uno de los comandos civiles del 55, y por supuesto que

Se trata de las siguientes entrevistas: Entrevista a Javier, Bahía Blanca, julio de 2013. Entrevista a Carlos, Capital Federal, agosto de 2013. Entrevista a Marcelo, Punta Alta, febrero de 2011. Entrevista a Omar, Olavarría, enero de 2014. Entrevista a Esteban, La Plata, agosto de 2013. Entrevista a Marcos, México, agosto de 2013. inundó a toda la familia de que ésta era la opción ética y política, digamos, eran los militares ¿no? Eran Aramburu y Rojas, él era suboficial, pero él de alguna manera irradiaba una especie de "sabiduría", entre comillas, hacia toda la familia, y bueno, este gorilaje que digo había en Bahía, venía también por esos lados, era un simple suboficial de marina, pero había intervenido en los comandos civiles y era un honorable señor que te hablaba de los filósofos griegos ¿no? (...) Nosotros teníamos una sociedad gorila, terriblemente reaccionaria alrededor nuestro, en nuestro inmediato, en nuestra cotidianeidad, en nuestros vecinos (Javier).

Éramos emisarios del afuera en una ciudad que sabíamos que era gorila y aparte lo vivíamos y lo sufríamos todos los días, era muy lenta la cosa en Bahía (...) es la ciudad más gorila y más reaccionaria de las que se pueden imaginar, bueno, estaba todo esto y todo esto durante muchas décadas, goteando todos los días no es poco (...) Yo recuerdo más una presencia fuerte de la marina de guerra, de los suboficiales de Puerto Belgrano, vistos hasta como ejemplo, gente fina, gente que jugaba rugby, que jugaba tenis, que daban lecciones de vida social de alguna forma, pero enemigos declarados del peronismo, por lo tanto la clase media, como la clase obrera, sobre todo ferroviaria, peronista, odiaba a los militares y los despreciaba, desde siempre, por lo menos desde el golpe del 55 (Carlos).

De acuerdo con los testimonios, todo aquello que podría ser considerado bajo el rótulo de 
antiperonista es equivalente a los términos "gorila" y "reaccionario". Esto es, las formas en que algunos sujetos refieren y perciben el conjunto de relaciones histórico-políticas que atravesaron Bahía Blanca a partir de 1955, condicionadas en gran medida por la presencia de la armada y definidas, a su vez, en términos de amigos/enemigos; una presencia que es señalada con énfasis, en tanto modelo de conducta a seguir. Gorila, en este contexto, constituiría además un valor político que evoca intereses contrapuestos $\mathrm{y}$, por ende, una sociedad dividida en amigos/enemigos según esos mismos intereses, o según ese modelo ejemplificado en la marina $y$, probablemente, en los sectores que se identificaban con ésta, en donde la política, o más bien el peronismo, resultaría el elemento de tensión en esa división. Cabría entonces hablar de la presencia de relaciones de poder que configuran los polos de esa tensión y que son identificados por los sujetos por medio de tres instituciones representativas de esos sectores.

Como iban armando la constitución de este sujeto, acá La Nueva Provincia fue siempre así, ése es el sujeto que [se] formó en esta zona, a-crítico, totalmente creído que si lo dice La Nueva Provincia es así, o sea que la realidad la construye siempre La Nueva Provincia (...) la iglesia cómplice en esto que todas las homilías de sus curas, todos los domingos con esta cuestión de la seguridad interna y ojo con los subversivos y todo lo demás (...) Nosotros nos hemos criado con la cultura de marina, pero en aquel tiempo los que eran militares pensaban que podían gobernar (...) en nuestra época, creo que muchos pibes se metían en Marina porque decían que en algún momento iban a ser gobernador (Marcelo).

Acá hubo una sintomatización bien pergeñada con La Nueva Provincia y por supuesto con las fuerzas armadas, no te olvides que está acá la Prefectura, está la Gendarmería, están las cuatro, la marina, la aviación, tenemos todo nosotros y $\mathrm{La}$ Nueva Provincia como ente doctrinario de lo que se propone, yo creo que acá en la zona es más fuerte La Nueva Provincia, doctrinariamente hablando, tiene su peso y llega a todos lados, llega a todas las casas, a las casas más humildes (Javier).

No solamente las tres fuerzas armadas que están ahí presentes (...) y una parte de la sociedad muy asociada a ese ambiente militar, sino que además la fuertísima presencia de La Nueva Provincia como formador de mentes durante décadas en Bahía Blanca, que tuvo una omnímoda presencia, y tuvo una absoluta y excluyente, porque no hubo otras alternativas comunicativas en ninguno de los medios, salvo su monopólico diario, monopólica radio, también apareció en la televisión, entonces esa omnímoda presencia era el otro gran factor de poder, era esto pero que tenía todo el sur, no solamente Bahía Blanca y docilizaban las mentes (...) Y el tercer factor es la iglesia, que después evidentemente dio muestras muy claras de en qué lado estaba, es decir, cuando nuestros familiares iban a preguntar por qué nosotros estábamos desaparecidos y él decía "por algo será" y les cerraba las puertas en las narices y tantas cosas más (Carlos). 
Los testimonios enuncian, a su vez, determinados aspectos que constituyen las relaciones de poder aludidas, y las que Carlos denomina como "polos formadores de la opinión pública bahiense", a saber, la formación de un sujeto a-crítico y/o la docilización de las mentes, la cultura de marina y el vínculo entre ambos, expresado a través de La Nueva Provincia como ente doctrinario. Siguiendo a Alcira Argumedo, todos estos aspectos se inscribirían en lo que la autora denomina como "matriz de pensamiento", en este caso de Bahía Blanca, conformada por "las sistematizaciones teóricas y las articulaciones coherentizadas" de los saberes y mentalidades "propios de distintas capas de la población de un país, de los cuales se nutren y a los que, a su vez, les ofrecen modalidades de interpretación tendientes a enriquecer los procesos del conocimiento y el desarrollo del sentido común" (2004: 85).

De esta forma, la presencia de las Fuerzas Armadas, a través de la imposición de normas y reglas que atañan estrictamente a lo militar y de su permanente control sobre la población; de La Nueva Provincia como formador de opinión pública, y; de la Iglesia como transmisora de "moralidad", sintetizan, a la vez que comunican, ciertas maneras de ver y percibir el mundo social. Parafraseando a Grüner (1997), podríamos decir que se trata de una "estrategia de dominio" violenta, en tanto atraviesa las relaciones sociales por medio del establecimiento de un orden determinado que se desarrolla, incluso, en lo cotidiano. No quedándose así en la mera presencia, en el hecho anecdótico del vecino militar, del discurso eclesial o del diario, se encuentra todo un conjunto de relaciones que conforman una subjetividad amenazada permanentemente por esa sensación de "vigilancia", sobre la sociedad y sobre cada sujeto en particular, asentada, a su vez, sobre procesos materiales y simbólicos.

Había una profusa presencia en todos los barrios de las fuerzas armadas, con lo que supone esa ideología y esa transmisión que destila gota a gota también su ideología y el control y la sensación de ciudad vigilada $y$, por otro lado, ideológicamente lo comunicativo y la iglesia como "reserva moral de la sociedad" (...) Teníamos vecinos militares, o del ejército, la marina, la marina tenía una influencia mayor a nivel cultural, o sea, le regalaba banderas a las escuelas, iba, llevaba la banda militar para que cantáramos el himno nacional, etc., todos teníamos algún vecino, o hermano de una novia o alguien que tenía que ver con los militares y una historia, también una historia antigua, o sea, mucha gente estaba asociada de alguna forma al ambiente militar (...) Desde siempre sospechábamos la presencia de espías permanentemente, no dentro de la agrupación política, pero sí que cualquier vecino, cualquier peluquero, cualquier compañero de rugby, nos terminara marcando como subversivos (Carlos).

En todo este contexto, las Fuerzas Armadas se fueron constituyendo en un actor central de la escena bahiense, en tanto hacedor y transformador de un tipo de subjetividad vinculada con lo militar. Esto es, elitista y estructurada, a la vez que estructurante, de las prácticas y concepciones de una parte de la sociedad bahiense. 
Las niñas de la sociedad bahiense ambicionaban ligarse con la camada de guardiamarinas, ésa era la percepción que teníamos a comienzos de la década del setenta. La marina como una casta social que suponía ascensión y brillo a las hijas de clase media que acudian a la universidad y el baile de promoción de los recién egresados, el ámbito donde reflejaban llegar a la cima. En el 68' los cursos de posgrado o de extensión universitaria rezaban en su convocatoria: "alumnos avanzados, graduados y oficiales de las fuerzas armadas" (Omar).

Si nosotros mirábamos para arriba generacionalmente, mirábamos un poco a ver qué habian hecho nuestros padres, resulta que nuestros padres era gente que pretendía una vida mejor, y si era posible, su hijo que sea cura o militar no había ningún problema, estaba todo bien, pero que lo ideal era que sea un próspero comerciante o un brillante profesional (Carlos).

"Recién después de 35 años estamos intentando rescatar del olvido para no cometer como dicen muchos investigadores de estos temas "Una nueva desaparición", que en nuestro caso es fácil de cometer por la impronta cultural que está impuesta de manera casi natural, por la dependencia que tenemos de la única fuente laboral que es la Base Naval Puerto Belgrano" (MoVeJuPA) ${ }^{11}$.

Publicación presentada por el Movimiento por la Verdad, la Memoria y la Justicia de Punta Alta (MoVeJUPA) en el VIII Foro Latinoamericano de Memoria e Identidad, realizado en octubre de 2011 en la ciudad de Montevideo, Uruguay (inédito).

Lo político, lo económico, lo social y lo cultural, habrían pasado, de esta forma, a hallarse determinados por este conjunto de relaciones de poder que atraviesan a los sujetos, de manera no siempre visible, tanto en el plano individual como colectivo. En el transfondo de este posicionamiento se encontraría la idea desarrollada por Grüner (1997) acerca de la violencia como constitutiva de la política. Una violencia que se desarrolla en el ámbito cotidiano y que, por ello, cimenta a la vez que amenaza los lazos sociales (Zukal y Noel 2010). Una violencia que deviene entonces en una "estrategia de dominio" de la política (Grüner 1997), ya no sólo representada por las Fuerzas Armadas, sino a la que se suman La Nueva Provincia y la Iglesia, conformando lo que Carlos denominara como "tres polos (de poder) formadores de la opinión pública bahiense".

En palabras de León Rozitchner (2003), se trataría del apoderamiento de la voluntad del otro para dominarlo en vida mediante el ejercicio del poder y la amenaza de darle muerte, a lo cual agrega que el sistema no es una estructura general concebida sin sujeto, el sistema aparece representado en quien ejecuta el crimen como un derecho propio, en este caso las tres instituciones mencionadas. Resulta interesante, en este sentido, destacar algunas posiciones respecto a cómo se percibía esa presencia cotidiana, de vigilancia, de las Fuerzas Armadas, más allá del hecho concreto destacado, de que en cada barrio si no tenías un agente de policía, tenías un suboficial del ejército, o tenías un suboficial de marina (Esteban).

Gran parte de la historia política de nuestro país, a lo largo de casi todo el siglo XX, nos habla de varios golpes de estado y democracias 
restringidas en manos de las fuerzas armadas, como representantes de diversos sectores de poder, tales como la burguesía agroexportadora e industrial y el capital monopólico (Calveiro 2005). En este proceso, las fuerzas armadas fueron ganando cada vez mayor poder $y$ autonomía, sin que ello suponga la ausencia de conflictos entre cada una de las fuerzas, tal es así que en los recuerdos de los sujetos entrevistados dichos conflictos se vivenciaban a través de distintos acontecimientos.

Yo vivía al lado del $V$ Cuerpo, a veces nos levantábamos, yo era chica, 9 o 10 años, $y$ a la madrugada sentíamos corridas y para mi mamá era "éstos ya se están peleando de vuelta", la Base, las revueltas, que cuando cayó Onganía, que cuando entra el otro, que se peleaban, y venía la Base contra el ejército y nos levantábamos a la mañana para ir a la escuela y ya estaba lleno de trincheras, estaban los tanques parados en la esquina de mi casa, o venían, te golpeaban: "se tienen que ir" y teníamos que juntar todo e irnos (Dora).

Este mayor empoderamiento de las Fuerzas Armadas también se habría visualizado en Bahía Blanca a través de diversas relaciones que éstas mantenían con la población civil, entre ellas las antes mencionadas por Omar y Carlos respecto de las cuestiones de ascenso y prestigio, y algunas otras definidas como de "prepotencia" por parte de los altos mandos del ejército y la marina, para con quienes realizaban el servicio militar tanto en una como en otra institución, o de "impronta cultural".

20 Si bien este tipo de relaciones fueron cambiando con las políticas en materia militar desde el 2003, durante las décadas que nos interesan, e incluso posteriormente, era común, según Horacio, ver a los milicos utilizando a los colimbas de chofer, de lustrabotas y de cadetes de las señoras. Las relaciones descritas como de impronta cultural que está impuesta de manera casi natural (Marcelo) se hallarían vinculadas con la dependencia laboral, tal como lo señaláramos con la cita del MoVeJuPA, principalmente para la ciudad de Punta Alta, pero también con el resto de las dependencias militares. Con el ámbito educativo, se vincularía en la medida que muchos de los profesores de algunos colegios eran suboficiales de marina, lo cual explicaría el fuerte impacto de la historia oficial, además de la presencia de la banda militar durante los actos escolares, el nombramiento de aulas con el nombre de altos miembros de las Fuerzas Armadas, entre otras actividades realizadas. Con el ámbito eclesial, se relacionaría a través de la doctrina que era transmitida por parte de algunos sacerdotes y, por último, con la micropolítica que se ejercía en los lugares de trabajo y en los sindicatos.

Yo iba a la escuela fábrica en frente de la plaza Rivadavia y todos los profesores eran zumbos de marina, eran todos suboficiales de marina los profesores nuestros, entonces cómo ibas a hablar, qué ibas a hablar. Los profesores del Goyena, o del Nacional, eran todos profesores de los sectores acomodados bahienses, qué iban a hablar, esos tipos iban a dar la historia oficial, no iban a profundizar en los temas que la gente había empezado a hablar en otros lados, y en los barrios se comenzó a hablar cuando aparecieron las unidades básicas. En cada barrio si no tenías un agente de policía, tenías un suboficial del 
ejército, o tenías un suboficial de marina (Esteban).

La iglesia cómplice en esto que todas las homilías de sus curas, todos los domingos con esta cuestión de la seguridad interna y ojo con los subversivos y todo lo demás y (...) la escuela también metiendo miedo o señalando gente, como lograron dominar absolutamente, creo yo, a toda esta sociedad, porque no puede ser que de otra manera, ésta fue una zona donde todo fue muy callado, muy ordenado y donde se sabía de que había sucedido un hecho que ellos denominaban subversivo y mucha gente acá decía "bueno, menos mal que estamos acá cerca de los militares" (Marcelo).

Quisiéramos resaltar la idea de la imposición como algo casi natural a la que se alude, o que subyace en los testimonios hasta aquí repuestos, y tensionarla con aquella esbozada por Marcelo acerca de la conformación de un sujeto a-crítico como parte de un mecanismo muy bien aceitado para que nadie piense, porque pensar era peligroso, cuando de lo que se trataba era de conformar un sujeto a-político y a-racional que se manejara casi de manera automática (Marcelo). En el transfondo de estos planteos pareciera subyacer, nuevamente, aquella definición de violencia como amenazadora de los lazos sociales y que, por ende, configuraría las relaciones entre unos y otros. Se trata de una trama compleja que se traduce en el día a día de las más diversas maneras. Esteban continuaba el relato presentado más arriba afirmando la falta de discusión política que se daba en distintos ámbitos de la vida cotidiana, como la familia, el trabajo, etc., con motivos de esta trama.
Lo cotidiano que yo recuerdo, no había discusiones que presentarían una sociedad en crisis, o una sociedad crítica, una cosa es una sociedad dormida como Bahía Blanca y otra cosa una sociedad cuando vos ves que la gente discute, no se metían, yo creo que la discusión arranca más que nada en el 73, era muy difícil convivir con eso, (...) Ilevar la discusión en la sociedad, la habían llevado adelante por ejemplo los sindicatos y la habían profundizado los sindicatos como la UOCRA (Unión Obrera de la Construcción de la República Argentina), se lleva a delante en la calle, en las unidades básicas ${ }^{12}$, en la universidad y en determinados sindicatos (Esteban).

No quisiéramos que a lo largo de este análisis lo político sea reducido al ejercicio de la violencia como dominio exclusivo de las tres instituciones en las que mucho hemos venido haciendo hincapié, en tanto centro de la política bahiense. Antes bien, la violencia aparece en la base de la política de estas instituciones, pero no de manera unidireccional y excluyente, es decir, no se ejerce sólo desde las instituciones hacia la sociedad. Es de la sociedad misma de la que emana dicha violencia y, en su naturalización como propia, la habilita a que encuentre un lugar de legitimación (Grüner 1997). Tal es así, que en los relatos acerca de las sensaciones que dicha legitimidad producía, aparecen las de vivir:

"[en] una burbuja aislada de los acontecimientos producidos en el país, como si en realidad ocurrieran en otro país, en donde lo común era escuchar

12 Locales destinados a actividades políticas en el marco del 21 
expresiones como "qué suerte que aquí no tenemos subversivos", "nosotros estamos bien seguros, estamos protegidos", "somos una ciudad sin problemas de tipo ideológico", y en la que siempre se defendía desde la prensa o el púlpito las acciones presentadas como heroicas por parte de las fuerzas armadas" (MoVeJuPA) ${ }^{13}$.

Esta connotación negativa acerca de Bahía Blanca y sus alrededores se transformó en una característica casi constante a lo largo de todo nuestro trabajo de campo. Mediados las más de las veces por su desenlace trágico, por la muerte y desaparición de muchos compañeros, por la imposibilidad de concretar los anhelos de aquellos años, los relatos presentes acerca del pasado raramente permiten entrever lo acontecido en términos de resistencia. Grüner, en su análisis acerca de la violencia como constituyente y constitucionalizante de la política, nos remite a una expresión de Octavio Mannoni que reza "ya lo sé pero aun así..." (1997: 48). La frase sintetiza incómodamente ese silencio, al cual Grüner llama "renegación", esto es, necesidad de obliterar de la memoria la percepción del terror impuesto por la violencia. Reponer no ya el terror, sino las estrategias resistentes, tal vez permita que éste pueda transitar por caminos menos dolorosos, menos desoladores. Estrategias orientadas hacia la desestabilización de los gobiernos militares, a contrarrestar los avances de La Nueva Provincia, a promover la apertura de discusiones políticas en diferentes ámbitos, a transgredir el cumplimiento del

$13 \quad$ Publicación presentada por el Movimiento por la Verdad, la Memoria y la Justicia de Punta Alta (MoVeJUPA) en el VIII Foro Latinoamericano de Memoria e Identidad, realizado en octubre de 2011 en la ciudad de Montevideo, Uruguay (inédito). orden hegemónico establecido, que es aquel promovido por las Fuerzas Armadas, La Nueva Provincia y la Iglesia.

Teniendo en cuenta que la mayor parte de los testimonios corresponden a sujetos con una identidad peronista, no sorprende que estas resistencias se enmarquen dentro del peronismo, resaltando fuertemente la importancia de la Resistencia Peronista, principalmente para el sector portuario y ferroviario, y más tarde, el Peronismo Revolucionario. Por supuesto que hubootras expresionesigualmentesignificativas, pero de acuerdo con la problemática aquí abordada, procuraremos puntualizar en aquellas vinculadas con el peronismo. De todos modos, cabe destacar brevemente algunos hechos que tuvieron lugar dentro del catolicismo, pero que aún así influyeron en la militancia peronista. En este sentido, Omar subraya que hubo una figura que tuvo gran ascendencia en la formación intelectual de muchos militantes, Benito Santechia, que incluso auspició un curso, en el Instituto Juan XXIII, sobre el diálogo cristiano-marxista y se abordaron teorías como las de Theilard de Chiardin y el marxista Roger Garaudy.

En relación específicamente con el peronismo, la universidad y un sector del gremialismo son señalados como los ámbitos en donde mayormente se producen experiencias que procuraron irrumpir en el orden establecido. En este sentido, Rozitchner (2003) nos diría, retomando la teoría de la guerra de Clausewitz, que toda violencia conlleva una contraviolencia.

Respecto de la universidad, ya sea en la Universidad Nacional del Sur, como en 
la Universidad Tecnológica Nacional, se destacan como "excepciones" algunas propuestas y miradas críticas de parte de ciertos profesores, sobre todo en Economía $y$, en menor medida, en el Departamento de Humanidades, principalmente las carreras de Letras e Historia. Estas expresiones, a las que se les sumaron ciertas lecturas como las de Hernández Arregui y John Williams Cooke, distintas formas de inteligir el contexto nacional con acontecimientos como el Cordobazo, el Tucumanazo, el Rosariazo y otras experiencias en el resto del continente, fueron despejándose de lo que Carlos denomina como el ropaje ideológico que cada uno tenía de sus propios orígenes y así se entiende, por ejemplo, cómo el hijo de una persona que tenía campo y que era de la clase media, relativamente acomodada, se radicalizaba y pasaba a militar en un espacio de izquierda o del peronismo.

Por el lado gremial, es significativo el papel de ATUNS (Asociación de Trabajadores de la Universidad Nacional del Sur), gremio que contaba con representantes de la Tendencia Revolucionaria y demás cuadros del peronismo combativo, y cuyo principal esfuerzo radicó en llevar adelante, dentro de la universidad, los puntos programáticos del gobierno peronista asumido en marzo de 1973 (Ferrari 2011). Todos estos elementos habrían dado lugar a que se generara una criticidad de nuevo tipo, o una ruptura de cascarón (Carlos), que conllevó la incorporación a la militancia de muchos jóvenes, docentes y no docentes de la universidad.

Entre los gremios que más se mencionan, en el sentido de adquirir mayor fuerza en la ciudad, se encuentran los ferroviarios de Ingeniero
White, Empleados de Comercio, la UOM (Unión Obrera Metalúrgica) y la UOCRA (Unión Obrera de la Construcción de la República Argentina), estos dos últimos nucleados en la Confederación General de los Trabajadores (CGT). La CGT tenía como secretario local a Rodolfo Ponce, sindicalista vinculado con los sectores burocráticos del sindicalismo peronista, con la Juventud Sindical Peronista y con la Triple $\mathrm{A}^{14}$.

En cuanto a la UOCRA, este gremio aparece, en algunos de los testimonios, como vinculado estrechamente a la universidad y como el espacio que comienza a dar muchas discusiones políticas en el seno de la sociedad bahiense, incluso antes de 1973. Se dice, entonces, que la discusión sale a la calle desde la universidad y desde los sectores populares, pero fundamentalmente desde la Juventud Peronista $^{15}$.

La explicitación de todas estas experiencias bien podría contradecir lo anteriormente dicho acerca de la renegación de las mismas, por lo menos en términos de su enunciación como algo trascendente. Más allá de su reposición, tales experiencias aparecen en las memorias como algo más bien efímero, transitorio. No obstante, la sorpresa ante ese algo efímero no pareciera tener tanto que ver con la brevedad del periodo transcurrido entre fines de 1972 y fines de 1974, y principios de 1975. La sorpresa ante ese algo efímero, más bien, se asocia a la idea de otredad, de un sujeto aislado en su propio territorio, que es visto por el resto de

\footnotetext{
Grupo parapolicial que dominó la escena política previo al golpe militar de 1976 y durante el mismo.

Una de las principales organizaciones políticas peronistas que nucleaba a la juventud.
} 
la sociedad con aquella distancia que ubica las cosas en el lugar de lo extraño. "Los que militábamos éramos como extraños, nos sentíamos extraños", sostenía Jorge. Para algunos se trató solamente de una cuestión que no iba más allá de discusiones en la universidad, para otros de un acercamiento transitorio de ciertos sectores, aunque para todos habría tenido que ver con la vigilancia que se vivía; con los valores que se ponían en juego; las miradas y los condicionamientos sociales, regidos siempre por el diario, la Iglesia y las Fuerzas Armadas. En este sentido, se remarca con énfasis que una vez que se desató el proceso represivo, hacia 1974, todas las conquistas políticas obtenidas se borraron con más facilidad, reconectándose nuevamente con su estado ideológico anterior, Bahía volvió a la "normalidad", entre comillas, Bahía volvió a ser lo que quiso La Nueva Provincia (Marcos).

Yo siento que nosotros éramos como unas especies de batallones combatientes frente a una sociedad que nos miraba perpleja, había cierto encapsulamiento, los tipos que nos miraban perplejos $y$ decian "¿éste quién es, qué hacen, están locos éstos?", porque nosotros éramos batallones, o militantes de una cosa que trascendía absolutamente a Bahía y éramos parte de una gesta colectiva que se estaba gestando en otros lados y nosotros, de alguna manera, en una sociedad muy difícil, en una sociedad muy terrible como Bahía, nosotros nos sentíamos como que teníamos que dar la lucha y teníamos que referenciar una contribución a lo otro que no estaba en Bahía, porque Bahía nos iba a seguir mirando desde sus persianas, desde sus mirillas de la puerta, nos iba a ver como bichos raros, salvo nuestra pequeña cápsula que entre nosotros discutíamos a ver si era mejor la lucha armada, o si era mejor la otra estrategia, discusiones que se daban en otro lado y que nosotros, de alguna manera replicábamos, pero eran discusiones áulicas dentro de la universidad, porque no pasaban de ahí (Carlos).

No sólo de extrañeza se trata, entonces, también emerge en los relatos la cuestión de la necesidad de generar en Bahía el mismo movimiento que se estaba produciendo en otros lugares dentro del país, pero en un contexto al cual se siente y se lo vive como ajeno y en el que, en cierta medida, se era ajeno. De ahí probablemente la referencia a la sensación de "encapsulamiento", contradictoria en tanto la militancia bahiense se vinculaba con el contexto nacional, y de una sociedad que tomaba distancia. Las miradas acerca de ello, o las sensaciones, son múltiples, quisiéramos por lo tanto reponer una más.

Creo que los Montoneros ${ }^{16}$ teorizaron sobre el papel que tenía que tener el activismo en Bahía Blanca, como que nosotros estuviéramos metidos en el corazón del enemigo y que nuestra acción iba a ser por eso tremendamente necesaria $y$ violenta, como que estábamos en el mero cuartel general de la derecha (...) digamos, ser un grupo de resistencia heroico $y$ súper organizado y súper militarizado, clandestinidad total (Marcos).

La afirmación de Marcos abre muchas preguntas, "hace ruido" podríamos decir de manera

\footnotetext{
$16 \quad$ Montoneros constituyó una de las principales organizaciones armadas durante gran parte de la década del setenta.
} 
más coloquial, interpela y se tensiona con esa idea de "ciudad vigilada", de disciplinamiento, de control, de "reserva moral", sostenida por ciertas instituciones hegemónicas, pero también por parte de ciertos sectores de la sociedad civil. A ello se refería Esteban en un testimonio ya citado, en cada barrio si no tenías un agente de policía, tenías un suboficial del ejército, o tenías un suboficial de marina, y Carlos cuando sostenía que cualquier vecino, cualquier peluquero, cualquier compañero de rugby, nos terminara marcando como subversivos. En los testimonios sobre lo singular de Bahía Blanca, la tensión entre lo particular y lo general, entre lo propio y lo ajeno, son variables sobre las que se va construyendo un imaginario sobre el que recae el conjunto de las relaciones sociales. La política media estas relaciones pero, a su vez, estas relaciones median la política. Queremos decir, si parte del imaginario sostenía que Bahía, siguiendo a Marcos y Carlos, era un "cuartel general" en el que había que dar una lucha que se estaba gestando en otro lado, ¿hasta qué punto tales relaciones podrían haber dado un giro significativo de no ser por una "contra-violencia"17? (Rozitchner 2003).

Todo ha sido hoy bastante elaborado, para algunos olvidado, para otros algo del pasado que se ha ido, o que simplemente se niega, o es renegado siguiendo a Grüner (1997). Mucho se insiste en que "esto era lo cotidiano en Bahía Blanca", un estado de vigilancia permanente, una moral establecida, una opinión pública bien formada y la imposibilidad de expresar nada que vaya por fuera de ese

León Rozitchner nos advierte sobre la posibilidad de equiparar violencia y contra-violencia. Plantea que la contra-violencia "es la que nos lleva a preservarnos de la muerte que quieren darnos, mientras que la violencia agresiva es indiferente frente a la muerte con tal de lograr su objetivo: es ofensiva" (2003: 106). orden establecido. Lecturas que conllevan que Bahía Blanca sea caracterizada como una ciudad gorila y reaccionaria al mismo tiempo que son señalados los distintos ámbitos en los que el peronismo pudo transgredir esa imagen. Más aún, ante esta "ciudad signada por la marina y el ejército", en tanto espacio ocupado, aparecen otros relatos, algunos más apasionados, otros más cuidados, supuestos y sensaciones verdaderamente legítimas, acerca de cómo la militancia atravesó esa cotidianeidad, ese espacio ocupado, dejando así su impronta. En este sentido, hemos procurado, al momento de poner en diálogo aquello que el sujeto narra acerca de su propia experiencia y nuestras aproximaciones a las mismas, no caer en el puro punto de vista, ni en discusiones meramente teóricas que escindan al propio sujeto en la reconstrucción del escenario etnográfico. Hemos procurado, también, dar cuenta de las contradicciones que emergen, no en un sentido negativo, sino en términos de cómo son reconstruidas hoy las memorias de ese pasado.

\section{Algunas consideraciones finales}

En una ciudad como Bahía Blanca, a la que muchos definen como una "ciudad vigilada" dada la fuerte presencia de las fuerzas armadas, las concepciones aludidas acerca de la militancia no sólo se inscriben en dicho contexto, sino que además determinan un conjunto de relaciones sociales particulares. En los relatos presentes aparecen, entonces, con fuerza esa sensación de control y vigilancia, de indiferencia de una parte importante de la sociedad, y de la militancia como una práctica acotada tan solo a un sector, en desacuerdo 
con la política imperante de Bahía Blanca y en correlación con lo que en otros lugares se venía dando, esto es, los que vivían la militancia desde una cierta "extrañeza".

Estamos viviendo con vecinos que fueron entregadores... todos sabemos quiénes eran (Raúl).

Tengo un dilema moral si está bien que yo cuente quién entregó y quién no porque me lo confiaron en una charla íntima unas alumnas (Patricia).

Me pasaba que yo creía que no tenía nada que contar y eso le pasa por ahí al que estuvo preso y volvió (...) Creo que no hay peor castigo que volver, porque acá tenías que callar todo y no decir nada, es complicado este momento y es complicado para la gente que sabe muchas cosas $y$ tiene miedo de hablar (Susana) ${ }^{18}$.

Estos registros, provenientes de entrevistas y de situaciones observacionales, ponen en escena un contexto disímil respecto a lo que en los últimos años ha ido ocurriendo en otros puntos del país, en donde los relatos y diversas formas de memorialización han alcanzado una visibilidad cada vez más grande, sobre todo en ciudades con mayor número de población. Como acontecimiento significativo podemos mencionar que en la ciudad de Punta Alta, en la cual se emplaza la Base Naval Puerto Belgrano, el primer registro de la realización de marchas en relación con la memoria es recién del 9 de julio de 2011, día en que se realizó un "desfile" en ocasión de la conmemoración de

18 Diálogo producido durante un taller de memoria realizado con el MoVeJuPA la autonomía de dicha ciudad, mientras que en otras localidades las marchas por la memoria llevan más de 20 años.

Podríamos plantear así que abordar la recreación de la experiencia política del sujeto militante de los años 70 , desde las posibilidades que la etnografía nos ofrece, no se limita a la descripción de las acciones que definen la práctica política (movilizaciones, actos relámpagos, charlas con los compañeros, trabajo de base, pintadas, toma de comisarías, etc.), ni a las concepciones que atraviesan dichas prácticas. Se trata, además, de dar cuenta de los sentidos que los mismos sujetos les atribuyen a tales prácticas y concepciones. De esta manera, en tanto la milicia pasaba a ser parte de la vida de una persona, en un contexto adverso, lo cotidiano de la política se traduce en lo cotidiano de la misma. El desafío, entonces, es distinguir una esfera de la otra para poder comprender cómo, en definitiva, ambas se entrecruzan y constituyen dos caras de una misma moneda.

Creemos hasta aquí haber señalado algunos puntos nodales que venimos trabajando en nuestra investigación, que hacen a una determinada manera de aproximarnos al pasado reciente, centrándonos para ello en las posibilidades que una mirada etnográfica ofrece. Mientras que para algunos la dificultad de narrar lo acontecido recae más bien en el miedo o en inquietudes de tipo "moral", para otros se ancla en un cuestionamiento más profundo hacia la dinámica misma de la organización de la que se formó parte. Para quienes se posicionan en un lugar que podríamos mencionar como "más crítico", la relación entre cómo se pensaba una práctica política determinada, cómo se la vivía 
y cómo se la recrea actualmente, constituye la base para una "transmisión lograda" (Hassoun 1996) del pasado a las nuevas generaciones.

El tema de la militancia, a pesar de la apertura que ha tenido durante los últimos años, continúa siendo un fenómeno a seguir debatiendo, principalmente en aquellos lugares cuyos contextos sociales permanecen más reticentes a volver sobre su propio pasado, tal es el caso, creemos, de Bahía Blanca y sus alrededores. Sin embargo, más allá de estos planteos y de los silencios aún persistentes, quisiéramos destacar aquellos relatos que nos hablan de las continuidades en términos de las políticas actuales, de la identificación con los jóvenes, que hoy día han elegido la militancia política como una opción válida para la transforma- ción, y de las posibilidades que para muchos significa poder contar su experiencia a otros. De esta manera, como punto de partida de este trabajo, el recorte realizado se inscribe en una forma particular de construcción de las memorias del pasado reciente, que se sostiene en la consideración de que la resignificación de aquel pasado "conflictivo" y la visualización de los silencios que aún persisten, permitirá que estos silencios puedan comenzar a transitar nuevos caminos. Principalmente respecto de cómo el sujeto presente se aproxima al pasado y a su propia experiencia de militancia política, ya desde una mirada crítica (política), ya desde una mirada más idealizada que, al mismo tiempo, nos permita dar cuenta de en qué medida las condiciones actuales de apertura facilitan una $u$ otra mirada.

\section{Bibliografía}

Argumedo, A. 2004. Los silencios y las voces en América Latina. Buenos Aires: Ediciones del Pensamiento Nacional.

Balbi, F. 2007. De leales, desleales y traidores. Valor moral y concepción de política en el peronismo. Buenos Aires: Antropofagia.

Bustos, R. y Marenco, N. 2000. "Proceso de reestructuración en una ciudad intermedia. Bahía Blanca”. Estudios Regionales Interdisciplinarios II. Bustos, R. y Cernadas, M. (Eds.). Bahía Blanca: UNS. 137-151.

Calveiro, P. 2006a. "Los usos políticos de la memoria". Sujetos sociales y nuevas formas de protesta. Caetano, G. (Ed.). Buenos Aires: CLACSO. 359-382.

2006b. "Testimonio y memoria en el relato histórico". Acta poética 27 (2): 65-86.

Carnovale, V., Lorenz, F. y Pittaluga, R. (Comps.). 2006. Historia, memoria y fuentes orales. Buenos Aires: Memoria AbiertaCedinci.

2005. Política y/o violencia. Buenos Aires:

Norma.

Cernadas, M. 1971. La creación de Puerto Belgrano y la política de poder en América del Sur. Punta Alta: Puerto Belgrano.

Ferrari, E. 2011. Unidad Básica Evita Montonera. Una experiencia política. Buenos Aires: Biliográfika.

Grüner, E. 1997. Las formas de la espada. Buenos Aires:
Hassoun, J. 1996. Los contrabandistas de la memoria. Buenos Aires: Ediciones de La Flor.

Jelin, E. 2009. “¿Quiénes? ¿Cuándo? ¿Para qué? Actores y escenarios de las memorias”. El Estado y la memoria. Gobiernos y ciudadanos frente a los traumas de la historia. Vinyes, R. (Ed.). Barcelona: RBA. 117-150.

Llull, L. 2005. "Introducción”. Prensa y política en Bahía Blanca. Bahía Blanca: UNS. 5-15.

Marenco, S. 2000. "De la ciudad baja de los años 50 a la moderna urbe de fin de siglo". La dinámica urbana. El proceso de desarrollo vertical y la problemática de la marginalidad urbana en Bahía Blanca. Formiga, N. y Marenco, S. (Coords.) Bahía Blanca: EdiUNS. 123-135.

Oberti, A. y Pittaluga, R. 2006. Memorias en montaje. Buenos Aires: El Cielo por Asalto.

Orbe, P. 2007. La política y lo político en torno a la comunidad universitaria bahiense (1955-1976). Estudio de grupos, ideologías y producción de discursos. Tesis de Doctorado en Historia, Universidad Nacional del Sur, Argentina.

Dumará

Peirano, M. 2001. O dito o feito. Río de Janeiro: Relume

Piña, C. 1986. "Sobre las historias de vida y su validez en las ciencias sociales". Documento de trabajo 319. Santiago de Chile: Programa FLACSO.

Pollak, M. y Heinich, N. 1986. "El testimonio". Actas de la Colihue. 
Investigación en Ciencias Sociales 62/63: 3-29.

Recchi, E. 1995. El ejército en Bahía Blanca: Acción y presencia. Buenos Aires: Círculo Militar.

Rodríguez, A., Tonellotto, S. y Bustos, R. 2000. "El puerto como espacio de debate en la discusión interdisciplinaria". Estudios Regionales Interdisciplinarios II. Bustos, R. y Cernadas, M. (Eds.). Bahía Blanca: UNS. 105-121.

Rozitchner, L. 2003. El terror y la gracia. Buenos Aires: Norma.

Sarlo, B. 2005. Tiempo pasado. Cultura de la memoria y giro subjetivo. Una discusión. Buenos Aires: Siglo XXI.

Sarasola, C. 1998. Los hijos de la tierra. Historia de los indígenas argentinos. Buenos Aires: Emecé.

Vezzetti, H. 2009. Sobre la violencia revolucionaria. Buenos Aires: Siglo XXI.
Weinberg, F. et al. 1978. Manual de historia de Bahía Blanca. Bahía Blanca: Universidad Nacional del Sur.

Zapata, B. 2008. "Prácticas de lucha y experiencia obrera en los gráficos de La Nueva Provincia (1973-1976)". Actas IV Jornadas de Trabajo sobre Historia Reciente. Rosario: Universidad Nacional de Rosario. Disponible en: http://www.riehr.com.ar/archivos/ Investigacion/Zapata.pdf (consultado en mayo de 2013). 2007. Páginas manchadas. Conflictividad laboral entre los gráficos y La Nueva Provincia en vísperas de la dictadura de 1976. Tesis de Licenciatura en Historia, Universidad Nacional del Sur, Argentina.

Zukal, J. y Noel, G. 2010. "Notas para una definición antropológica de la violencia: Un debate en curso". Disponible en: http://ppct.caicyt.gov.ar/index.php/publicar/article/view/1191 (consultado en mayo de 2013). 